\title{
Predicting spring barley yield from variety-specific yield potential, disease resistance and straw length, and from environment-specific disease loads and weed pressure
}

\author{
Hanne Østergård · Kristian Kristensen • \\ Hans O. Pinnschmidt • Preben Klarskov Hansen • \\ Mogens S. Hovmøller
}

Received: 11 April 2008/Accepted: 7 May 2008/Published online: 6 June 2008

(C) Springer Science+Business Media B.V. 2008

\begin{abstract}
For low-input crop production, well-characterised varieties increase the possibilities of managing diseases and weeds. This analysis aims at developing a framework for analyzing grain yield using external varietal information about disease resistance, weed competitiveness and yield potential and quantifying the impact of susceptibility grouping and straw length scores (as a measure for weed competitiveness) for predicting spring barley grain yield under variable biotic stress levels. The study comprised 52 spring barley varieties and 17 environments, i.e., combinations of location, growing system and year. Individual varieties and their interactions with environments were analysed by factorial regression of grain yield on external variety information combined with observed environmental disease loads and weed pressure. The external information was
\end{abstract}

H. Østergård (两)

Biosystems Department, Ris $\varnothing$ National Laboratory for Sustainable Energy, Technical University of Denmark, P.O. Box 49, Roskilde 4000, Denmark

e-mail: hanne.oestergaard@ risoe.dk

K. Kristensen

Faculty of Agricultural Sciences, Department of Genetics and Biotechnology, University of Aarhus, Foulum,

Tjele 8830, Denmark

H. O. Pinnschmidt · P. K. Hansen · M. S. Hovmøller Faculty of Agricultural Sciences, Department of Integrated Pest Management, University of Aarhus, Flakkebjerg, Slagelse 4200, Denmark based on the official Danish VCU testing. The most parsimonious models explained about $50 \%$ of the yield variation among varieties including genotypeenvironment interactions. Disease resistance characteristics of varieties, weighted with disease loads of powdery mildew, leaf rust and net blotch, respectively, had a highly significant influence on grain yield. The extend to which increased susceptibility resulted in increased yield losses in environments with high disease loads of the respective diseases was predicted. The effect of externally determined straw length scores, weighted with weed pressure, was weaker although significant for weeds with creeping growth habit. Higher grain yield was thus predicted for taller plants under weed pressure. The results are discussed in relation to the model framework, impact of the considered traits and use of information from conventional variety testing in organic cropping systems.

Keywords Yield loss analysis - Low-input · Genotype-environment interaction . Powdery mildew $\cdot$ Leaf rust $\cdot$ Scald . Net blotch - Weed ground cover

\section{Introduction}

Spring barley is an important crop for food and feed in many cereal production areas in Europe. The grain yield of a variety in any environment is influenced by 
genotype of the variety, i.e., its yield potential, its disease resistance and weed competitiveness as well as by the potential yield (sensu Evans and Fischer 1999) obtainable in a given environment. Further, the environmental load of biotic and abiotic stresses as well as variable crop management practices, soil types and weather determine the actual yield. Assessing varietal characteristics and their potential interactions with different cropping environments is therefore crucial in modern low-input barley production where management inputs are restricted. For instance, in organic farming, no chemical herbicides and fungicides may be used to control weeds and diseases, respectively. The control of these biotic stresses thus mainly depends on crop rotation, mechanical weeding and choice of varieties having sufficient weed competitiveness and resistance to prevalent diseases (Wolfe et al. this issue; Bond and Grundy 2001).

In several European countries, varietal characteristics of cereals are assessed through the variety approval system (VCU-testing for Variety Cultivation and Use) where yield potential in absence of disease, disease resistance properties, quality parameters and, in some countries, weed competitiveness are measured/assessed (e.g. NIAB 2008; Bundessortenamt 2007; Dansk Landbrugsrådgivning 2007, $2008 \mathrm{a}, \mathrm{b})$. The ratings of varietal traits are often expressed on an ordinal scale, for example on a scale ranging from 1 to 9 . This can only slightly take the impact of environmental variability into account and does not express the relative importance of individual varietal traits in relation to grain yield. Information on varietal characteristics of specific relevance for organic farming systems is even more scarce. This is partly because the effect of tolerance or resistance to various stresses cannot directly be estimated under organic conditions where comparisons of diseased and weed infested plots and corresponding pesticidetreated disease- and weed-free control plots may not exist.

Data on disease-induced yield losses, whether obtained from official variety testing or other yield loss studies, are typically based on field trials with and without disease control. Regression models may be applied to such data using different response functions. For example, yield loss data may be regressed on linear combinations of various covariates, such as measures of intensity of different diseases, crop characteristics and their products (Madden and Nutter 1995). Other statistical models have been used to examine the influence of genotype specific covariates on yield loss either obtained from the experimental data analysed (internal) or from other sources (external). For example, a linear mixed model was used to estimate disease-related yield losses in winter wheat, using external information on varietal disease resistance and earliness as well as estimates of environment-specific disease intensities as covariates (Zhang et al. 2007). Survey data consisting of yield information of characterised varieties in characterised environments has been analysed using other types of models aiming at describing as much of the yield variation between varieties and their interactions with the environments as possible, using environment-specific covariates (e.g. levels of biotic and abiotic stresses, climatic factors) as well as variety-specific covariates (e.g. disease susceptibility, lodging, earliness). Different kinds of factorial regression have been applied to that type of data, for example to analyse genotypeenvironment interactions for seed yield in perennial ryegrass (Van Eeuwijk and Elgersma 1993) and for winter wheat grain yields (Brancourt-Hulmel et al. 2000).

The influence of weed pressure on yield loss has been investigated as related to varietal competitiveness (e.g. Christensen 1995; Lemerle et al. 1995). Competitiveness against weeds can be looked at in two ways: either as the ability of a crop to maintain the yield in the presence of weeds (tolerance to competition; Goldberg 1990) or as the ability to reduce weed growth (suppression of competitors; Tilman 1990). The former is most related to studies of yield loss whereas the latter is more relevant in relation to direct effects on the weeds (Hansen et al. 2008). Straw length has been shown to be the most important factor for weed suppressive ability and also indirectly for minimising yield loss in the presence of weeds (Lemerle et al. 1995).

The analyses presented here are based on survey type data and combine multiple and factorial regression methods to estimate how environmental variation due to a number of biotic stresses differently influence the performance of varieties with different characteristics. The models serve multiple purposes: (1) to develop a framework for estimating grain yield using external (VCU) varietal information 
about yield potential, disease resistance and straw length (weed competitiveness) in combination with internal environmental data on disease load and weed pressure, and (2) to quantify the impact of grouping varieties for susceptibility to four foliar diseases and for straw length (weed suppression) for predicting spring barley grain yield. The biotic stresses considered were powdery mildew (Blumeria graminis $\mathrm{f}$. $\mathrm{sp}$. hordei), leaf rust (Puccinia hordei), leaf scald (Rhynchosporium secalis), net blotch (Pyrenophora teres) and different groups of weed species classified into creeping, annual tall and perennial weeds.

\section{Materials and methods}

\section{Field experiments}

Field trials were conducted 2002-2004 in experimental research fields at three Danish locations, Research Centre Flakkebjerg (sandy loam), Research Centre Foulum (loamy sand), and St. Jyndevad Research Station (coarse sand). Additional trials were carried out in 2005 at Research Centre Foulum and at Dalmose (sandy loam, near Flakkebjerg). The trials represented crop management strategies ranging from low-input 'conventional' systems with herbicides and mineral fertilization, but no fungicide application, over systems conducted under simulated organic conditions with no herbicides and fungicides to certified organic crop management practices. The 'organic' systems comprised trials with and without undersown clover grass mixtures, the former with no added nutrients and the latter with a reduced rate of organic slurry and a weed harrowing strategy that included one pre-emergence weed harrowing and 1-3 post-emergence weed harrowings to keep the weed pressure manageable (see Hansen et al. 2008). All trials were laid out in incomplete block designs using two or three replicates ( $\alpha$-design, Patterson et al. 1978). Seventeen combinations of crop management strategy, location and year were assessed and analysed as unique 'environments'.

\section{Selection of varieties}

A total of 150 spring barley varieties were investigated, the majority consisting of entries considered for approval for the Danish Cereal Variety List, whereas a few were included on the basis of desirable traits for low-input production, e.g. enhanced root growth, nutrient uptake and weed competitiveness. In the present analyses, we included all varieties which had been investigated in field trials for at least 2 years and for which VCU information about grain yield potential, disease susceptibility for the considered diseases and straw length was available (see below), i.e., a total of 52 varieties, varying from 21 to 52 at the individual years and locations.

Observations and internal characteristics of environments

Each plot was assessed for a large number of characteristics. For this study we included: grain yield at $85 \% \mathrm{DM}$, disease severity for each of the four prevailing foliar diseases, powdery mildew (Blumeria graminis), leaf rust (Puccinia hordei), net blotch (Pyrenophora teres) and scald (Rhynchosporium secalis), and \% ground cover of weeds and undersown clover grass mixtures. Grain yield was the dependent variable in the models and observations of diseases and weeds were used to characterise the 17 environments as internal regression variables in the models.

For each environment, disease load for each of the four diseases was estimated as 95 percentiles of single plot disease severity assessments. These percentiles represented the disease severity of highly susceptible varieties across varieties in a specific field trial. Disease severity (\% leaf area of top three leaves on a scale with 11 classes $(0 \%, 0.01 \%$ (trace), $0.1 \%$, $0.5 \%, 1 \%, 5 \%, 10 \%, 25 \%, 50 \%, 75 \%$ and $100 \%)$ ) was assessed two to three times during the season. In order to make disease data comparable across site and year, one single disease severity value corresponding to growth stage 70 (beginning of grain filling) for each combination of variety, disease and environment was calculated by linear interpolation. These disease severities were subsequently transformed to their third root to achieve linearity between them and the dependent variable (logarithm of grain yield).

Further, for each environment, weed pressure was estimated as 95 percentiles of single plot non-crop plant ground cover. These percentiles represented the weed pressure of varieties with reduced competitiveness across varieties in a specific field trial. Infestation of weeds and undersown clover grass mixtures was assessed for the organically managed 
environments as $\%$ ground cover, once or twice per plot, between 22 and 90 days later than the last weed harrowing to ensure appropriate regrowth of the weeds. No weed records were made in the conventionally managed environments, which were treated with herbicides. The four most prevalent dicotyledonous weed species per environment were assessed individually whereas the less frequent were classified into one common class ('others'). Perennial and tall weeds were assessed on the basis of individual species in environments where these were considered significant according to Hansen et al. (2008). Three non-crop plant categories were defined for this study: annual tall weeds, perennial weeds and creeping weeds where the latter category included the class 'others' and in environments with undersown clover grass mixtures also these plants. The $\%$ ground cover assessments were third root transformed.

\section{External characteristics of varieties}

Independent information about varieties with respect to grain yield potential and straw length (as a measure of weed competitiveness) as well as disease susceptibility for the considered diseases was obtained from external (VCU testing) sources as explained below. The external variety characteristics were all used as either classification variable or covariates in the different statistical models.

External characteristics for grain yield and straw length were computed from the official Danish testing of cereal varieties (Dansk Landbrugsrådgivning 2008b), i.e., from 35 field trials (4-10 trials per year in the years 1999-2004). These experiments were generally treated with pesticides a number of times and in a dose concordant with the Danish Pesticide Action Plan (Jørgensen and Kudsk 2006), i.e. biotic stresses were controlled effectively for varieties of relevance for agriculture in Denmark whereas highly susceptible varieties may have suffered from disease. For each of the traits grain yield and straw length, means of recorded values, one for each combination of environment and variety, were analysed in a joint regression analysis (cf. Digby 1979) to estimate a variety specific mean and a variety specific slope. Based on the variety specific means, varieties were assigned to five equally spaced intervals (score groups). For yield potential, the length of the interval was $2.1 \mathrm{hkg} \mathrm{ha}^{-1}$ whereas it was $4.5 \mathrm{~cm}$ for straw length.
Information on variety specific disease resistance was obtained from the groupings in 'Crop Protection Online' (CPO) according to Dansk Landbrugsrådgivning (2008a). Four disease susceptibility groups are defined here: 0 (resistant), 1, 2 and 3 (very susceptible). The groupings in Crop Protection Online are updated each year, thereby representing the current susceptibility of each variety to each disease as reflected by the prevalent pathogen population (Hovmøller and Henriksen 2008). In most cases, the groupings did not change during the considered field trial period 2002-2005. When the CPO-grouping for a variety was changed, the grouping for 2003 was chosen for varieties present in trials only in 2002 and 2003. For varieties included in 3 or 4 years, the most frequent or the most recent grouping was chosen.

\section{Statistical models}

The grain yield data from the actual field trials were described by the dependent variable $\left(Y_{v r b e}\right)$ recorded for variety $v$ in block $b$ of replicate $r$ in environment $e$ (incomplete block design of type $\alpha$-design, with each block containing a fraction of all varieties and with blocks grouped to form two or three complete replicates). These observations were analysed in three steps after a logarithmic transformation. At first the observations were adjusted for variation between plots within each environment (model A) to provide the estimated means $G_{e v}$ and their residual variances $\sigma_{e}^{2}$ for the following analyses. Next step was to define the basic model for the data model B0, which was a mixed model for all environments with environment as fixed effect. Finally, regression of $G_{e v}$ on external variety characteristics and internal environmental characteristics were performed (models B1 and B2 as well as C1 and C2). In models B1 and B2 no interactions between biotic factors were included; the models $\mathrm{C} 1$ and $\mathrm{C} 2$ included interactions.

\section{Model A}

An estimate of the logarithmic grain yield for each variety in each environment was derived using the model for the $\alpha$-design in each environment.

$\log Y_{v r b e}=\theta_{e}+\tau_{e v}+\delta_{r e}+B_{r b e}+H_{v r b e}$

where $Y_{v r b e}$ is the yield recorded for variety $v$ in block $b$ of replicate $r$ of environment $e ; \theta_{e}, \tau_{e v}$, and $\delta_{r e}$, are 
the fixed effects of yield levels for environment $e$, variety $v$ in environment $e$, and replicate $r$ in environment $e$, respectively; $B_{r b e}$ and $H_{v r b e}$ are the random effects of block $b$ in replicate $r$ in environment $e$ and the residual effect of plot $v r b$ in environment $e$, respectively; $B_{r b e}$ and $H_{v r b e}$ are assumed to be independent and normally distributed with mean 0 and variance $\sigma_{B e}^{2}$ and $\sigma_{H e}^{2}$, respectively.

Model A was applied for each environment and the mean logaritmic yield for variety $v$ in environment $e, G_{e v}$, and the residual variance, $\sigma_{e}^{2}$ from model A were defined as:

$G_{e v}=\hat{\theta}_{e}+\hat{\tau}_{e v}$

$\hat{\sigma}_{e}^{2}=\frac{1}{k_{e}\left(k_{e}-1\right)} \sum_{i=1}^{k_{e}-1} \sum_{j=i+1}^{k_{e}} \operatorname{VAR}\left(G_{e i}-G_{e j}\right)$

where $k_{e}$ is the number of varieties for environment $e$ and $\operatorname{VAR}\left(G_{e i}-G_{i j}\right)$ is the variance on the difference between variety $i$ and $j$ in environment $e$.

\section{Model BO}

The basic model was fitted to the data in order to estimate the variance components for the main effect of variety and for the interaction effect of variety $\times$ environment, respectively.

$G_{e v}=\mu_{e}+D_{v}+E_{e v}+F_{e v}$

where $\mu_{e}$ is the fixed effect of environment $e ; D_{v}, E_{e v}$ and $F_{e v}$ are the random effects of variety, environment $\times$ variety and residual variability, respectively; $D_{v}, E_{e v}$ and $F_{e v}$ are assumed to be independent and normally distributed with mean zero and variances $\sigma_{D}^{2}, \sigma_{E}^{2}$ and $\hat{\sigma}_{e}^{2}$, respectively, with $\hat{\sigma}_{e}^{2}$ estimated in model A.

We assume that B0 gives the unbiased estimate of variance components for the population from which the used varieties and environments can be regarded as a representative sample.

\section{Model Bl}

This model assumes that some of the variability in yield caused by variety and the interaction between environment and variety can be explained by characteristics of the varieties estimated from other sources (external characteristics). The model assumes

no interactions among fixed effects of biotic stresses. Mathematically this implies:

$$
\begin{aligned}
& G_{e v}=\mu_{e} \\
& +\alpha_{m_{v}}^{m}+\beta_{m_{v}}^{m} m_{e} \\
& +\alpha_{r_{v}}^{r}+\beta_{r_{v}}^{r} r_{e} \\
& +\alpha_{b_{v}}^{b}+\beta_{b_{v}}^{b} b_{e} \\
& +\alpha_{s_{v}}^{s}+\beta_{s_{v}}^{s} s_{e} \\
& +\alpha_{l_{v}}^{l}+\beta_{l_{v}}^{a} a_{e}
\end{aligned}
$$

$$
+\beta_{l_{v}}^{p} p_{e}
$$$$
+\beta_{l_{v}}^{c} c_{e}
$$$$
+\alpha_{y_{v}}^{y}
$$$$
+D_{v}+E_{e v}+F_{e v}
$$

$+D_{v}+E_{e v}+F_{e v}$

where superscripts for $\alpha$ and $\beta$ identify the different traits and subscripts the group to which the variety belongs; $m_{v}, r_{v}, b_{v}$ and $s_{v}$ are $0,1,2$ or 3, depending on the suceptibility group of variety $v$ for the respective disease, $l_{v}$ and $y_{v}$ are $1,2,3,4$ or 5 , depending on the score group of variety $v$ for the respective trait, and other variables are defined previously.

For all parameters, a weighted summation restriction was applied, i.e., for the effect of powdery mildew we have:

$$
\sum_{m=0}^{3} n_{m} \hat{\alpha}_{m_{v}}^{m}=\sum_{m=0}^{3} n_{m} \hat{\beta}_{m_{v}}^{m}=0, \text { where } n_{m} \text { is the num- }
$$

ber of varieties in powdery mildew suceptibility group $m_{v}$, and $\hat{\alpha}_{m_{v}}^{m}$ and $\hat{\beta}_{m_{v}}^{m}$ are the estimates of the effects of varieties in powdery mildew suceptibility group $m_{v}$. 
The $\alpha$ and $\beta$ parameters estimate the effects on yield from varieties of a specific group either in case of no environmental load $(\alpha)$ or as the regression on the environmental load $(\beta)$. As the powdery mildew susceptibility group 0 was divided into varieties possessing powdery mildew resistance due to the mlo resistance gene and those having other sources of major gene resistance to powdery mildew, a submodel was considered with 2 subgroups of powdery mildew susceptibility group 0 . In the following models, the two subgroups were merged because subgrouping did not improve the fit.

\section{Model B2}

In model B2 the number of parameters is reduced compared to model B1 by assuming linearly decreasing or increasing effects on grain yield of the respective traits with respect to the variety groups. For example, for powdery mildew, $\alpha_{m_{v}}^{m}$ and $\beta_{m_{v}}^{m}$ was described by the following equations:

$\alpha_{m_{v}}^{m}=\mu_{\alpha}+\alpha^{m} m_{v} \quad$ and $\quad \beta_{m_{v}}^{m}=\mu_{\beta}+\beta^{m} m_{v}$

where $\mu_{\alpha}$ and $\mu_{\beta}$ are intercepts that will be absorbed by the fixed environmental effects, $\mu_{e}$. Substituting this into the expression for powdery mildew in model B1, 8 parameters (2 for each susceptibility class) are reduced to $2\left(\alpha^{m}\right.$ and $\left.\beta^{m}\right)$.

The parameter $\alpha^{m}$ may be interpreted as the difference in effect on yield (yield loss) of varieties belonging to adjacent susceptibility groups, e.g. group 0 and 1 or group 2 and 3, when no disease is present, and $\beta^{m}$ is the weight on the disease load when estimating the difference in effect on yield (yield loss) of the disease load for varieties belonging to adjacent susceptibility groups.

Similar reductions were carried out for the other effects so that model B2 could be expressed as:

$$
\begin{aligned}
G_{e v}= & \mu_{e}+\alpha^{m} m_{v}+\beta^{m} m_{v} m_{e}+\alpha^{r} r_{v}+\beta^{r} r_{v} r_{e}+\alpha^{b} b_{v} \\
& +\beta^{b} b_{v} b_{e}+\alpha^{s} s_{v}+\beta^{s} s_{v} s_{e}+\alpha^{l} l_{v}+\beta^{a} l_{v} a_{e} \\
& +\beta^{p} l_{v} p_{e}+\beta^{c} l_{v} c_{e}+\alpha^{y} y_{v}+D_{v}+E_{e v}+F_{e v}
\end{aligned}
$$

where symbols follow the same principles as above.

\section{Model C1}

In order to examine whether the effects of environmental characteristics were additive, as assumed in model $\mathrm{B} 1$ and $\mathrm{B} 2$, the model $\mathrm{C} 1$ was constructed as an extension of B2 including cross-products of regression variables for all the individual traits:

$$
\begin{aligned}
G_{e v}= & \mu_{e}+\alpha^{m} m_{v}+\beta^{m} m_{v} m_{e}+\alpha^{r} r_{v}+\beta^{r} r_{v} r_{e}+\alpha^{b} b_{v} \\
& +\beta^{b} b_{v} b_{e}+\alpha^{s} s_{v}+\beta^{s} s_{v} s_{e}+\alpha^{l} l_{v}+\beta^{a} l_{v} a_{e} \\
& +\beta^{p} l_{v} p_{e}+\beta^{c} l_{v} c_{e}+\alpha^{y} y_{v}+\gamma^{m r} m_{v} m_{e} r_{v} r_{e} \\
& +\gamma^{m b} m_{v} m_{e} b_{v} b_{e}+\gamma^{m s} m_{v} m_{e} s_{v} s_{e}+\gamma^{r b} r_{v} r_{e} b_{v} b_{e} \\
& +\gamma^{r s} r_{v} r_{e} s_{v} s_{e}+\gamma^{b s} b_{v} b_{e} s_{v} s_{e}+\gamma^{a p} l_{v} a_{e} l_{v} p_{e} \\
& +\gamma^{a c} l_{v} a_{e} l_{v} c_{e}+\gamma^{p c} l_{v} p_{e} l_{v} c_{e}+\gamma^{m a} m_{v} m_{e} l_{v} a_{e} \\
& +\gamma^{r a} r_{v} r_{e} l_{v} a_{e}+\gamma^{b a} b_{v} b_{e} l_{v} a_{e}+\gamma^{s a} s_{v} s_{e} l_{v} a_{e} \\
& +\gamma^{m p} m_{v} m_{e} l_{v} p_{e}+\gamma^{r p} r_{v} r_{e} l_{v} p_{e}+\gamma^{b p} b_{v} b_{e} l_{v} p_{e} \\
& +\gamma^{s p} s_{v} s_{e} l_{v} p_{e}+\gamma^{m c} m_{v} m_{e} l_{v} c_{e}+\gamma^{r c} r_{v} r_{e} l_{v} c_{e} \\
& +\gamma^{b c} b_{v} b_{e} l_{v} c_{e}+\gamma^{s c} s_{v} s_{e} l_{v} c_{e}+D_{v}+E_{e v}+F_{e v}
\end{aligned}
$$

where $\gamma$ parameters are the interaction effects between the respective traits with symbols as before.

One way of interpreting the parameters of this model is to look at each interaction term $\gamma$ as a factor which implies that one variable (e.g. a specific disease) changes the effect of another variable. As an example to demonstrate the influence of powdery mildew on leaf rust, the relevant model terms can be rewritten as:

$\beta^{r} r_{v} r_{e}+\gamma^{m r} m_{v} m_{e} r_{v} r_{e} \Leftrightarrow\left(\beta^{r}+\gamma^{m r} m_{v} m_{e}\right) r_{v} r_{e}$

showing that the regression on leaf rust disease load depends on the disease load of powdery mildew. Now $\beta^{r}$ is the effect of leaf rust only when a variety is resistant to powdery mildew or when powdery mildew is absent.

\section{Model C2}

Successive reductions of the model $\mathrm{C} 1$ were carried out by removing the least significant effects one by one. Some restrictions were imposed during the reduction process: A parameter included in model B1 was not removed until all interactions involving that parameter were excluded from the model nor was the $\alpha$-term removed if there was a significant effect of the corresponding biotic effect ( $\beta$-term). When all remaining effects were significant at the $5 \%$ significance level, the reduction was stopped. It is important to notice that non-significant effects may still be present due to the restrictions. 
After these reductions, the following model C2 was reached:

$$
\begin{aligned}
G_{e v}= & \mu_{e}+\alpha^{m} m_{v}+\beta^{m} m_{v} m_{e}+\alpha^{r} r_{v}+\beta^{r} r_{v} r_{e} \\
& +\alpha^{b} b_{v}+\beta^{b} b_{v} b_{e}+\alpha^{l} l_{v}+\beta^{c} l_{v} c_{e}+\alpha^{y} y_{v} \\
& +\gamma^{m r} m_{v} m_{e} r_{v} r_{e}+D_{v}+E_{e v}+F_{e v}
\end{aligned}
$$

where all symbols are as in the previous models.

In order to evaluate how important each disease, diseases in general, score for yield potential and straw length were in explaining the effect of genotype main effect and genotype $\times$ environment interaction, the effect of each of these factors were successively left out of the model $\mathrm{C} 2$.

\section{Model choice, parameter estimation and testing}

The parameters of all models were estimated using the method of maximum likelihood and the theory of mixed models (see e.g. McCulloch and Searle 2001). All calculations were carried out using the procedure MIXED of SAS (SAS Institute 2000).

The significance of individual parameters in the model was tested using $F$-tests based on the estimated variance components and the principles of Satterthwaite (1946) for determining the denominator degree of freedom. The different models were compared using log likelihood tests based on 2 times the $\log$ of the likelihood when one of the models were an extension of the other. When this was not the case the models were compared by means of the following measures: the AIC criterion (Akaike 1974), the BIC criterion (Schwarz 1978) and the variance components of variety and interaction between variety and environment. The criteria AIC and BIC are based on 2 times the $\log$ of the likelihood adjusted in order to penalize for the number of parameters in the model: the more parameters the larger is the adjustment (for details, see Akaike (1974) and Schwarz (1978)).

Variance components for variety, variety $\times$ environment and the sum of these two terms were used to evaluate how much of the genetically related variation revealed in model $\mathrm{B} 0$ could be explained by including covariates in the models.

\section{Results}

The 52 varieties in this study represented a broad range of characteristics as judged from VCU testing information (Tables 1 and 2). Sixty percent of the varieties were resistant against powdery mildew (50\% containing the mlo resistance gene), about $5 \%$ showed high levels of resistance to leaf rust and scald, respectively, and even fewer were resistant against net blotch. The varieties had yield potentials in the range from 61.7 to $72.4 \mathrm{hkg} \mathrm{ha}^{-1}$ with a symmetrical distribution of yield scores. Most varieties were characterised as having low to high straw length; seven varieties were classified as very short (range $53.0-56.9 \mathrm{~cm}$ ) and only one variety was characterised as very tall (range 71.0-75.5 cm).

The 17 environments were characterised with respect to the levels of biotic stresses on the basis of 95 percentiles of observed values (across varieties) of the four prevalent diseases and of ground cover of three types of non-crop plants (Table 3). The large diversity in varietal characteristics combined with big differences in biotic stresses and nutrient inputs (data not shown) resulted in great variability in grain yield values across environments, i.e., ranging from 31.7 to $72.5 \mathrm{hkg} \mathrm{ha}^{-1}$ expressed by the 95 -percentiles. The biotic stress covariates varied from $0.0 \%$ weed ground cover (for herbicide-treated plots) to $100.0 \%$ for undersown plots. The powdery mildew disease loads ranged from $0.5 \%$ to $45.9 \%$ leaf coverage, leaf rust from $0.0 \%$ to $5.2 \%$, scald from $0.0 \%$ to $15.1 \%$, and net blotch from $0.1 \%$ to $23.1 \%$ (Table 3).

Of the genetically related variation in grain yield (sum of the variance components for variety and variety $\times$ environment interaction, respectively), $60 \%$ was variation among varieties independent of the environment (model B0, Table 4). The B1-model hypothesised that some of this genetically related yield variation could be explained by external characteristics: (1) the disease susceptibility grouping taking the disease load into account in the considered environment, (2) straw length score of the varieties taking the weed pressure into account in the considered environment, and (3) the varietal yield potential (yield score obtained in high input trials where diseases and weeds were chemically controlled). This model explained $58 \%$ of the genetically related variation revealed in B0 mainly by reducing the variation among varieties (the variance component for variety). The variation explained by model B1 was almost independent of whether the powdery mildew resistant varieties were considered as one group or as two separate groups for varieties 
Table 1 Number of varieties in disease susceptibility groups 0 to 3 as defined by Crop Protection Online (Dansk Landbrugsrådgivning 2008a)

\begin{tabular}{lllll}
\hline Disease (symbol) & 0: Resistant & 1: Slightly susceptible & 2: Susceptible & 3: Very susceptible \\
\hline Powdery mildew $(m)$ & $31(26)^{\mathrm{A}}$ & 4 & 10 & 7 \\
Leaf rust $(r)$ & 2 & 25 & 19 & 6 \\
Net blotch $(b)$ & 10 & 17 & 20 & 5 \\
Scald $(s)$ & 3 & 28 & 14 & 7 \\
\hline
\end{tabular}

A Number of varieties with the mlo-gene are indicated in parenthesis

Table 2 Number of varieties in groups for grain yield potential and straw length scores as recalculated from the Danish official variety testing (Dansk Landbrugsrådgivning 2008b)

\begin{tabular}{llllrr}
\hline Trait (symbol) & 1: Very low & 2: Low & 3: Medium & 4: High & 5: Very high \\
\hline Grain yield potential score $(y)$ & 7 & 13 & 20 & 8 & 4 \\
Straw length score $(l)$ & 7 & 17 & 16 & 11 & 1 \\
\hline
\end{tabular}

Table 3 Environmental characteristics of the 17 environments measured as 95\%-percentiles based on all single plot observations in this environment

\begin{tabular}{|c|c|c|c|c|c|c|c|c|}
\hline \multirow[t]{2}{*}{ Environment $^{\mathrm{A}}$} & \multirow{2}{*}{$\begin{array}{l}\text { Grain yield } \\
\left(\mathrm{hkg} \mathrm{ha}^{-1}\right)\end{array}$} & \multicolumn{3}{|c|}{ Non-crop plants ${ }^{\mathrm{B}}$ ( $\%$ ground cover) } & \multicolumn{4}{|c|}{ Disease load (\% leaf coverage) } \\
\hline & & $\begin{array}{l}\text { Annual tall } \\
\text { weeds }\end{array}$ & $\begin{array}{l}\text { Perennial } \\
\text { weeds }\end{array}$ & $\begin{array}{l}\text { Creeping } \\
\text { weeds } \mathrm{C}\end{array}$ & $\begin{array}{l}\text { Powdery } \\
\text { mildew }\end{array}$ & $\begin{array}{l}\text { Leaf } \\
\text { rust }\end{array}$ & Scald & $\begin{array}{l}\text { Net } \\
\text { blotch }\end{array}$ \\
\hline Fou05_u & 31.7 & 31.0 & 0.0 & 100.0 & 0.5 & 0.1 & 0.4 & 2.9 \\
\hline Jyn04_u & 41.4 & 0.0 & 0.0 & 80.0 & 10.6 & 0.1 & 0.0 & 23.1 \\
\hline Dal05_o & 45.8 & 7.0 & 1.3 & 10.0 & 9.0 & 2.6 & 0.0 & 8.9 \\
\hline Fla04_o & 52.9 & 45.0 & 3.8 & 75.0 & 5.1 & 5.2 & 0.0 & 9.5 \\
\hline Jyn04_o & 54.5 & 10.0 & 0.0 & 45.0 & 18.0 & 0.1 & 0.0 & 23.1 \\
\hline Fou05_o & 56.9 & 65.7 & 0.0 & 75.0 & 3.9 & 0.7 & 0.9 & 8.1 \\
\hline Fou02_c & 58.7 & - & - & - & 37.3 & 3.7 & 15.1 & 2.2 \\
\hline Fou04_u & 59.1 & 0.0 & 0.0 & 62.5 & 17.4 & 0.0 & 0.0 & 0.1 \\
\hline Fla02_o & 59.4 & 18.5 & 3.0 & 22.5 & 0.5 & 0.5 & 0.1 & 4.8 \\
\hline Jyn03_o & 59.9 & 12.0 & 0.0 & 41.8 & 45.9 & 0.0 & 0.1 & 3.1 \\
\hline Fou03_o & 61.5 & 30.0 & 1.3 & 55.0 & 7.9 & 0.1 & 0.1 & 4.8 \\
\hline Fou03_c & 61.9 & - & - & - & 7.9 & 0.0 & 4.8 & 7.6 \\
\hline Fou02_o & 62.0 & 8.8 & 0.0 & 20.0 & 18.6 & 2.2 & 3.7 & 5.9 \\
\hline Fla02_c & 62.8 & - & - & - & 1.0 & 1.0 & 1.0 & 1.0 \\
\hline Fla03_o & 64.0 & 5.0 & 2.2 & 40.0 & 3.0 & 0.5 & 0.1 & 5.0 \\
\hline Fou04_o & 64.6 & 0.0 & 0.0 & 52.7 & 31.9 & 0.0 & 0.0 & 0.1 \\
\hline Fla03_c & 72.5 & - & - & - & 0.5 & 0.4 & 0.3 & 3.6 \\
\hline
\end{tabular}

$\overline{\mathrm{A}}$ The environment coding is 3 letters for location, 2 digits for year, 1 letter for management $(\mathrm{u}=$ undersown, o simulated organic, $\mathrm{c}=$ low-input conventional)

B In the low-input conventional environments, herbicides were applied and weeds were not recorded but set to zero in the analyses

C For definition of this class see "Materials and methods"

possessing the mlo-gene or other powdery mildew resistance genes (data not shown).

The parameters $\alpha$ and $\beta$ (model B1) estimated the contribution of the different factors to yield of varieties of a specific susceptibility group or straw length score group either in case of no environmental load $(\alpha)$ or as the regression on the environmental load $(\beta)$. Since the data were log-transformed, these 
Table 4 Comparison of the different models

\begin{tabular}{|c|c|c|c|c|c|}
\hline Criteria & B0 & B1 & B2 & $\mathrm{C} 1$ & $\mathrm{C} 2$ \\
\hline Number of fixed effects (excl. 17 environments) & - & 38 & 13 & 34 & 10 \\
\hline \multicolumn{6}{|l|}{ Variance components ${ }^{\mathrm{A}}$} \\
\hline Variety $^{\mathrm{A}}$ & 38.16 & 7.00 & 11.67 & 11.51 & 11.85 \\
\hline Variety $\times$ environment ${ }^{\mathrm{A}}$ & 25.78 & 19.68 & 21.31 & 20.42 & 21.11 \\
\hline $\operatorname{Sum}^{\mathrm{A}}$ & 63.94 & 26.68 & 32.98 & 31.93 & 32.96 \\
\hline Variation explained by model compared to B0 (\%) & - & 58 & 48 & 50 & 48 \\
\hline \multicolumn{6}{|l|}{ Information criteria } \\
\hline $2 \log \mathrm{L}$ (large is better) ${ }^{\mathrm{B}}$ & 1533 & $1707 * * *$ & $1661 * *$ & $1680 \mathrm{~ns}$ & $1661 \mathrm{~ns}$ \\
\hline AIC (large is better) & 1495 & 1595 & 1597 & 1574 & 1603 \\
\hline BIC (large is better) & 1457 & 1485 & 1534 & 1471 & 1547 \\
\hline
\end{tabular}

estimates represented approximate relative grain yield effects, i.e. change in grain yield due to the influence of the corresponding trait. The estimated $\alpha-$ and $\beta$-values for each susceptibility group were plotted against the group number for each disease (Fig. 1). The $\alpha$-values increased with increasing susceptibility group number, although not consistently for powdery mildew. The $\beta$-values decreased with increasing susceptibility group number. Figures 2 and 3 showed such linearly increasing trends also for the $\alpha$-values of the grain yield and straw length score groups, respectively. Figure 4 indicated linearly increasing trends for the $\beta$-values of the straw length score group for perennial and creeping weeds (middle and bottom panel of Fig. 4) but an decreasing trend with respect to tall annual weeds (top panel of Fig. 4).

Figures 1-4 indicated that the parameters $\alpha$ and $\beta$ were proportional to the susceptibility group number or growth characteristic score group. The reformulation of model B1 to the more parsimonious model B2 reduced the explained genetically related yield variation from $58 \%$ to $48 \%$, but the information criteria BIC judged model B2 to be better than model B1 because the fewer parameters in B2 more than outweighed the increase in unexplained variation (Table 4).

Model $\mathrm{C} 1$, which comprised the potential interactions between disease effects and weed effects, increased the explained variation slightly, but both information criteria became smaller and a likelihood ratio test was not significant (Table 4). Model C2, which was derived by reducing model $\mathrm{C} 1$ by omitting non-significant effects, resulted in a more parsimonious model explaining $48 \%$ of the genetically related variation in model $\mathrm{B} 0$ with only 10 parameters. The yield potential score group played an important role, with an average yield difference of $4 \%$ among individual groups (Table 5). A variety in yield score group 5 thus would yield almost $16 \%$ more than a variety in group 1. Among the disease-related effects, only those involving powdery mildew, leaf rust and net blotch as well as the interaction between powdery mildew and leaf rust were significant. The disease load parameters indicated that leaf rust had the highest yield reducing effect per environmental disease load unit, followed by net blotch and powdery mildew. The positive parameter for the interaction between leaf rust and powdery mildew indicated that the combined effect was less than additive.

Since both information criteria suggested $\mathrm{C} 2$ as the best model, yield predictions were obtained from model $\mathrm{C} 2$ for a range of scenarios by implementing the parameters shown in Table 5. As expected, increasing environmental disease loads of a disease resulted in increasing yield losses (decreasing yield gains), depending on the disease and the susceptibility group of the variety (Fig. 5, top panels and bottom left panel). However, particularly for net blotch, being in susceptibility group 0 was disadvantageous at a low disease load. The non-additive effect on yield losses when powdery mildew and leaf rust occurred at the same time was demonstrated for a variety belonging to susceptibility group 3 for both powdery mildew and leaf rust (group 3 variety) 

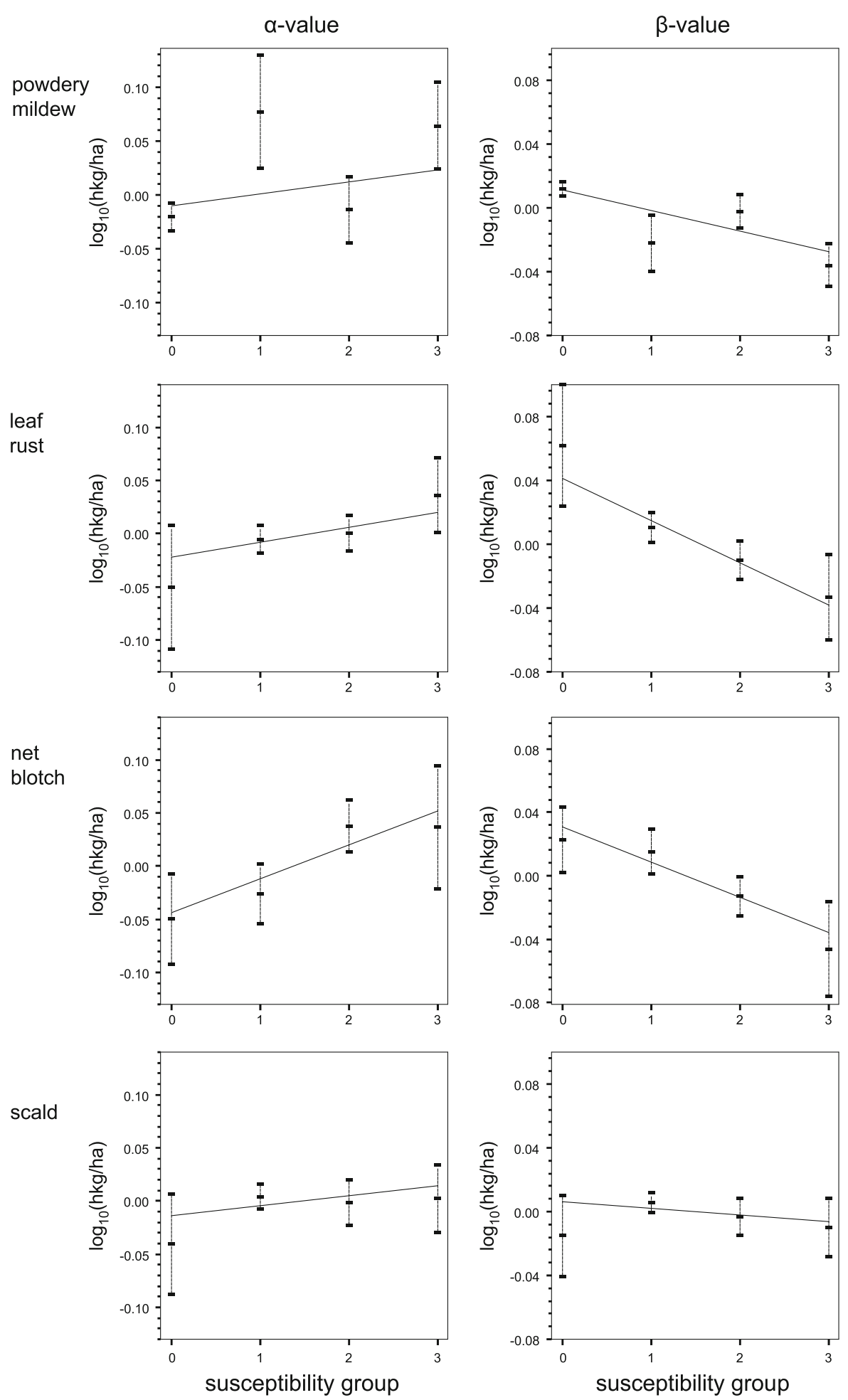

Fig. 1 Estimated $\alpha$-values and $\beta$-values for different susceptibility groups for four diseases (left panel $=\alpha_{m_{v}}^{m}$, right panel $=\beta_{m_{v}}^{m}$ etc) as estimated using model B1 (mean parameter estimates and $95 \%$ confidence limits). The lines are drawn based on estimates from model B2 


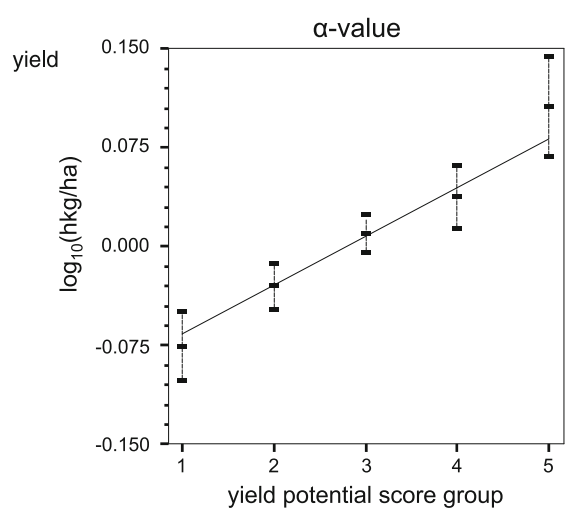

Fig. 2 Estimated $\alpha$-values for different yield potential score groups as estimated using model B1 (mean parameter estimates and $95 \%$ confidence limits). The lines are drawn based on estimates from model B2

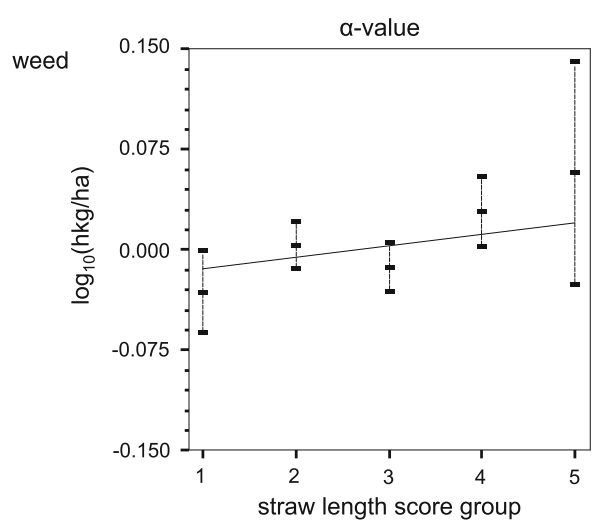

Fig. 3 Estimated $\alpha$-values for different straw length score groups as estimated using model B1 (mean parameter estimates and $95 \%$ confidence limits). The lines are drawn based on estimates from model B2

relative to the yield of a variety in susceptibility 0 for both diseases (Fig. 6). To exemplify, 4\% leaf rust alone would result in $13 \%$ yield loss for a group 3 variety while $10 \%$ powdery mildew alone would cause $10 \%$ yield loss as compared to a disease free situation. However, the loss for a group 3 variety when both diseases were present at these disease loads compared to the situation without disease would be approximately $16 \%$ which is $7 \%$ less than the sum of loss due to each individual disease.

For weed infestation only creeping weeds had a significant effect (Table 5). Increasing pressure of creeping weeds resulted in increasing yield losses, with short varieties suffering most and tall varieties least (right bottom panel of Fig. 5).
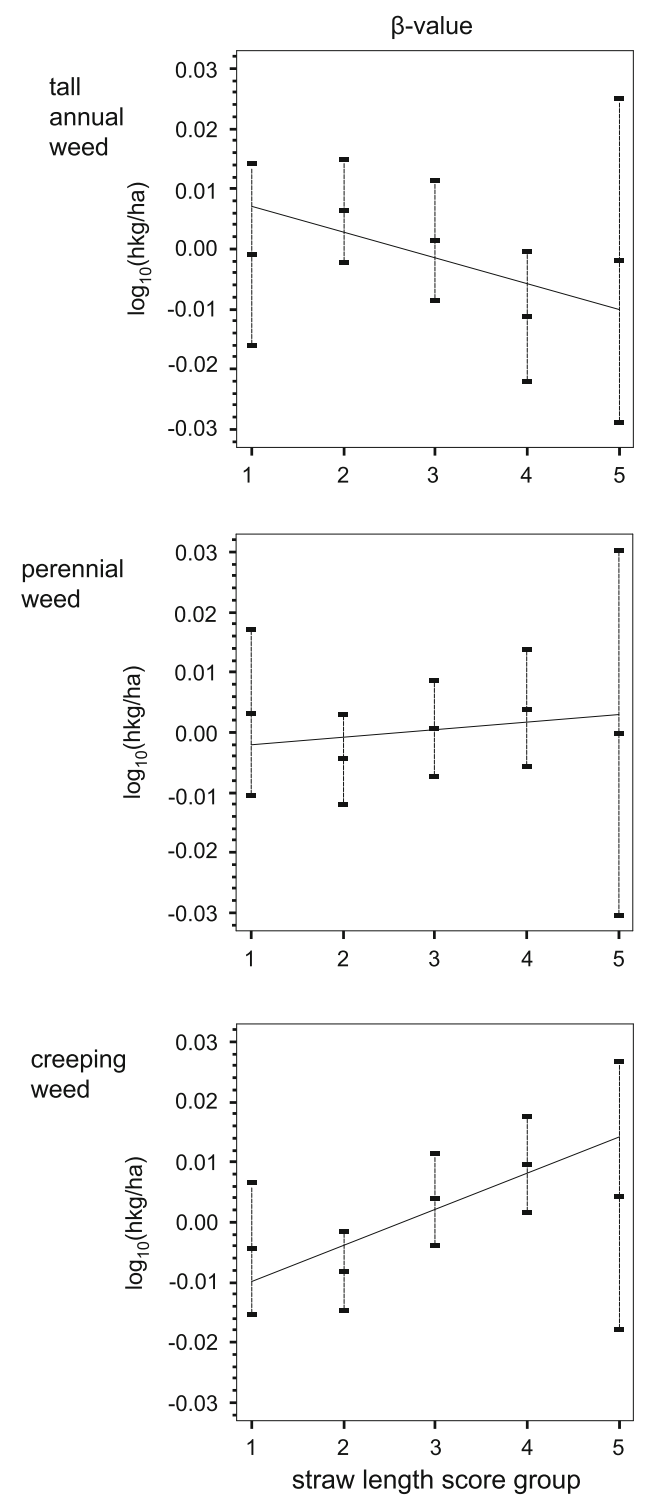

Fig. 4 Estimated $\beta$-values for different straw length score groups for three types of non-crop ground cover as estimated using model B1 (mean parameter estimates and 95\% confidence limits). The lines are drawn based on estimates from model B2

The importance of different factors in the $\mathrm{C} 2$ model was judged by comparing the decrease in explained grain yield variation if a factor was removed from the model. The yield potential score grouping was the most important factor for describing yield variation (Table 6) because exclusion of this effect reduced the explained yield variation by half (from $48 \%$ to $24 \%$ ). Among the diseases, powdery 
Table 5 Parameter estimates and their standard errors for the model C2

\begin{tabular}{llr}
\hline Covariate (symbol) & $\alpha^{\mathrm{A}}$ & $\beta$ and $\gamma^{\mathrm{B}}$ \\
\hline Grain yield (y) & $0.0383 \pm 0.0052^{* * *}$ & $-0.0147 \pm 0.0024 * * *$ \\
Powdery mildew (m) & $0.0118 \pm 0.0072 \mathrm{~ns}$ & $-0.0268 \pm 0.0061^{* * *}$ \\
Leaf rust (r) & $0.0144 \pm 0.0089 \mathrm{~ns}$ & $-0.0202 \pm 0.0054 * * *$ \\
Net blotch (b) & $0.0300 \pm 0.0114^{* *}$ & $0.0019 \pm 0.0009 *$ \\
Mildew $\times$ rust $(\mathrm{m} \times \mathrm{r})$ & & $0.0036 \pm 0.0013^{* *}$ \\
Straw length (l) & & $0.0098 \pm 0.0070 \mathrm{~ns}$ \\
\hline
\end{tabular}

A Yield change (log hkg ha ${ }^{-1}$ ) between varieties in two adjacent groups

B Yield change (log hkg ha ${ }^{-1}$ ) per unit change in product of variety group number and (environmental characteristic) $)^{1 / 3}$

A, B The asterisks show the significance of the hypothesis that the parameter is equal to zero (ns: $P>0.05, * P<0.05, * * P<0.01$, *** $P<0.001)$

C Note that weed infestation refers to creeping weeds

mildew contributed most in explaining yield variation.

\section{Discussion}

The present models made it possible to compare the impact of varietal disease susceptibility, grain yield potential and straw length scores on grain yield for a range of environments differing in potential yield levels and levels of biotic stresses. Such information is important as decision support for prioritising resource allocation in agricultural research, breeding and practical crop management. The biotic stresses considered were powdery mildew (Blumeria graminis f. sp. hordei), leaf rust (Puccinia hordei), scald (Rhynchosporium secalis), net blotch (Pyrenophora teres), and different botanical classes of weeds and undersown clover grass mixtures. External variables for variety characteristics were used as covariates, i.e., the official VCU grouping for disease susceptibility in 'Crop Protection Online' (Dansk Landbrugsrådgivning 2008a), as well as grouping based on scores for straw length and yield potential from high-input field trials. In other studies (e.g. Zhang et al. 2007; Østergård et al. 2005), also earliness had a significant influence on yield, and lodging tolerance and leaf area index (LAI) may be equally important varietal characteristics. However, information on earliness and LAI was not available for all our field trials and lodging occurred very infrequently. This type of information was therefore not included.
The 17 environments (combinations of year, location and growing system) represented many agro-ecological conditions under which spring barley is currently grown in temperate climates regarding potential yield level (sensu Evans and Fischer 1999), soil type, weather conditions, low-input crop management and biotic stresses. Scald, however, was occurring rather erratically and at low levels implying that the estimated effects of disease load and varietal resistance may not be as representative for scald as for the other three diseases. Also, there may be other yield-constraining biotic and abiotic factors, such as other diseases and specific nutrient problems that were not covered in this study. The 52 varieties represented many combinations of the varietal characteristics; however, this cannot exclude non-random associations of traits within varieties. Despite such limitations, the statistical modelling allowed realistic deductions as to how and to which extent spring barley yield is being affected by varietal properties interacting with biotic stresses.

Model framework

Genotype-environment interactions have been analysed by means of various statistical techniques, such as multiple regression, joint regression, factorial regression, principal component analyses and clustering methods (for a review see e.g. Lin et al. 1986; Kang and Gauch 1996; Piepho 1998; Kristensen and Hill 2002). The type of models used here can be regarded as both a simplification and an extension of factorial regression models as introduced by Denis 
Fig. 5 Relative yield gain in environments with different disease loads of the three significant diseases and creeping weeds (see "Materials and methods" for definition) predicted for varieties belonging to different susceptibility groups and straw length score groups, respectively. Note that the scales on the $x$-axes are different for the different traits
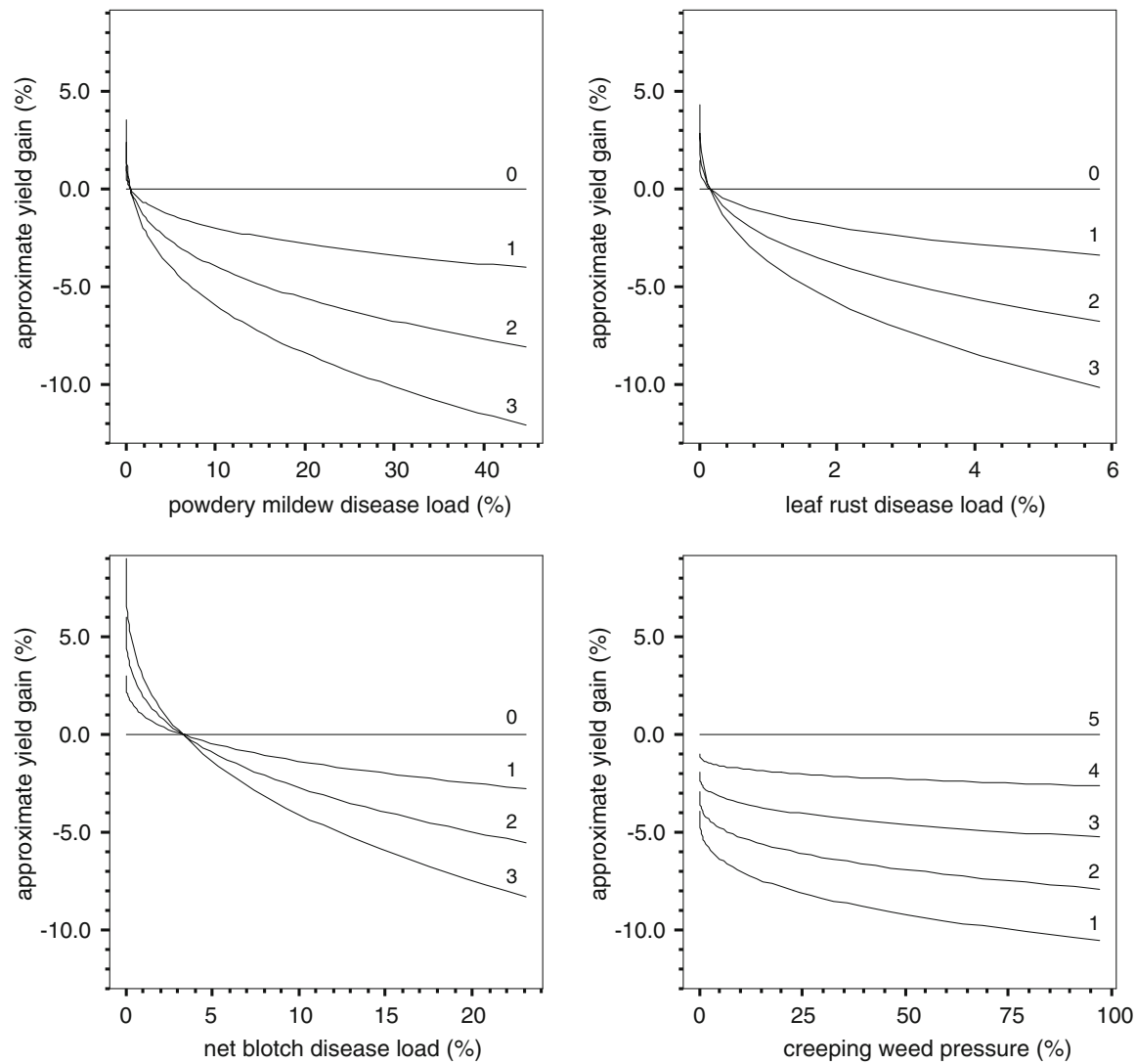

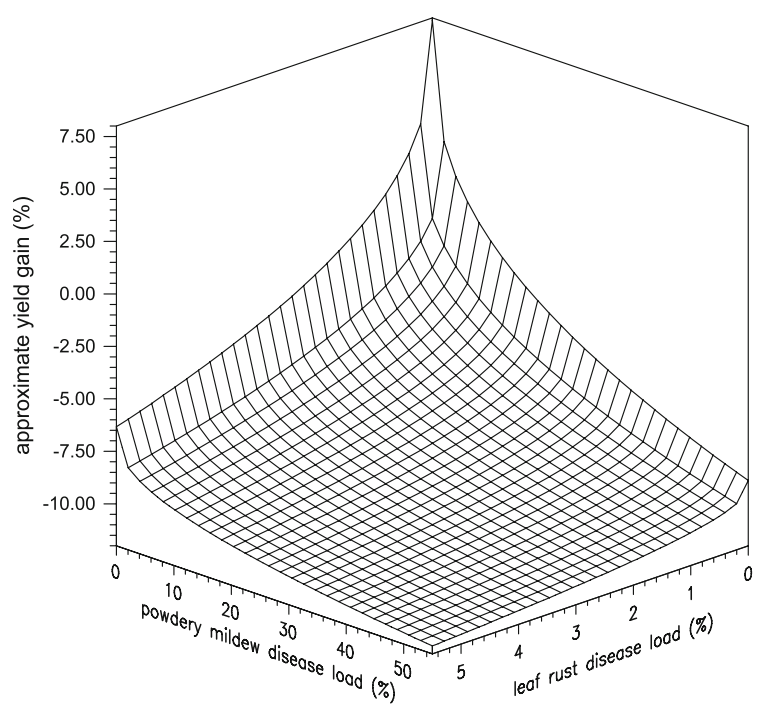

Fig. 6 Predicted yield gain of varieties in powdery mildew as well as leaf rust susceptibility group 3 as related to varieties in susceptibility groups 0 of both diseases shown as function of disease loads of powdery mildew and leaf rust
(1980). In the general setup of factorial regression, usually all combinations of environmental and genotypic covariates are included in the model. Our models did not include main effects of environmental covariates because modelling of environmental effects was not the scope of the study; the differences between environments were taken into account by allowing a separate intercept for each environment. Compared to factorial regression, the model was extended by allowing the effect of different environmental factors (diseases and/or weeds) to interact. These interactions were formulated in a similar way as in response surface models (see e.g. chapter 15 of Box et al. 1978), but without including the quadratic terms usually included in these models.

The covariates used in the present models were external VCU genotypic covariates and internal environmental covariates. This principle was also applied by Baril et al. (1995), Paul et al. (1993) and Zhang et al. (2007) for describing the genotypeenvironment interaction for potatoes, sugar beets and 
Table 6 Comparison of the effect of omitting different factors included in the model C2

\begin{tabular}{|c|c|c|c|c|c|c|c|}
\hline Criteria & $\mathrm{C} 2$ & $\begin{array}{l}\text { Grain yield } \\
\text { score omitted }\end{array}$ & $\begin{array}{l}\text { Straw length score } \\
\text { (and weed) omitted }\end{array}$ & $\begin{array}{l}\text { Powdery mildew } \\
\text { omitted }\end{array}$ & $\begin{array}{l}\text { Leaf Rust } \\
\text { omitted }\end{array}$ & $\begin{array}{l}\text { Net blotch } \\
\text { omitted }\end{array}$ & $\begin{array}{l}\text { All diseases } \\
\text { omitted }\end{array}$ \\
\hline \multicolumn{8}{|l|}{ Variance components ${ }^{\mathrm{A}}$} \\
\hline Variety $^{\mathrm{A}}$ & 11.85 & 27.20 & 14.17 & 14.14 & 11.91 & 11.83 & 14.02 \\
\hline Variety $\times$ environment & 21.11 & 21.22 & 21.48 & 23.17 & 22.47 & 21.96 & 25.18 \\
\hline $\operatorname{Sum}^{\mathrm{A}}$ & 32.96 & 48.42 & 35.65 & 37.31 & 34.38 & 33.79 & 39.20 \\
\hline Variation explained $(\%)^{\mathrm{B}}$ & 48 & 24 & 44 & 42 & 46 & 47 & 39 \\
\hline \multicolumn{8}{|l|}{ Information criterias } \\
\hline $2 \log \mathrm{L}$ (large is better) ${ }^{\mathrm{C}}$ & 1661 & $1624 * * *$ & $1647 * * *$ & $1619 * * *$ & $1638 * * *$ & $1647 * * *$ & $1587 * * *$ \\
\hline AIC (large is better) & 1603 & 1568 & 1593 & 1567 & 1586 & 1593 & 1543 \\
\hline BIC (large is better) & 1547 & 1514 & 1540 & 1516 & 1536 & 1541 & 1500 \\
\hline
\end{tabular}

winter wheat, respectively. Others, such as Van Eeuwijk et al.(1995) used independent environmental covariates (such as climate variables) while Kristensen and Ericson (2008), using some of the same data as presented here, applied internal genotypic covariates to describe the relationship between growth characteristics and yield. As in our models, the model used by Zhang et al. (2007) describing genotypeenvironment interactions for winter wheat varieties included also the product of varietal susceptibility and corresponding disease load as covariates and a linear effect of disease load to partly explain the variation between environments. However, they did not include the effect of varietal susceptibility in disease-free environments nor did they consider straw length and weed pressure. Instead, they included variety earliness. Neither was varietal yield potential included as a covariate in their model because their data were derived from pairs of trials with and without disease control. In our survey data, the varietal yield potential was a very important term for reducing the random variation and for avoiding possible bias caused by genetic correlations between the external covariates disease susceptibility, straw length and yield potential.

In all models presented here, the effect of environment was assumed to be fixed. The models B2, C1 and C2 explained each about $50 \%$ of the genetically related variation revealed in model B0 and yield variation caused by varieties was generally better explained than yield variation due to interactions between the variety and the environment. One reason for this may be that the models did not consider environment-specific yield determining factors such as nutrition-related covariates. The variety by environment variance components found here seemed to be smaller than those found by Baril et al. (1995), Van Eeuwijk et al. (1995) and BrancourtHulmel et al. (2000) as their models explained more than $50 \%$ of the interaction sum of squares. However, their models were less parsimonious than ours because they all used individual variety slopes for the environmental covariates whereas our models assumed variety slopes determined by external ordinal-scaled covariates consisting of only 4-5 levels. Our approach requires fewer parameters and is likely to be more robust and allowing a higher degree of generalisation than other approaches. Zhang et al. (2007) found that their model explained $23 \%$ of the variability caused by trial $\times$ cultivar interaction. Van Eeuwijk and Elgersma (1993) reviewed a number of examples with grasses where regression-type methods explained between $12 \%$ and $55 \%$ of the interaction sum of squares. In this light, the level of yield variation explained in our study was satisfactory and the factorial regression-type models (B2, C1 and C2) applied here gave a good description of the data although there were some inconsistencies regarding the parameter estimates for powdery mildew (Fig. 1). The latter is also reflected by the likelihood ratio tests (Table 4) as B2 fitted the data significantly less well than model B1. However, Akaike's (AIC) and 
Schwartz's (BIC) information criteria both indicated that model B2 was to be preferred because it required fewer parameters. With regard to significance, the models B2, C1 and C2 fitted equally well to the data, but model $\mathrm{C} 2$ was chosen as the final description because it was more parsimonious than the other two models.

Impact of disease resistance and weed competitiveness

A major objective of the present study was to examine the value of external varietal information obtained by VCU testing for predicting grain yield under variable levels of disease severities and weed pressure. Grain yield score from the VCU trials was the most significant predictor for the actual grain yield, accounting for about $50 \%$ of the yield variation explained by all covariates (Table 6). Further, the disease resistance grouping was overall a better predictor for yield than the straw length grouping, suggesting that the genetic potential for disease control may be higher than the genetic potential for weed control as measured by straw length. However, straw length is only one of several components influencing weed competitiveness (Hansen et al. 2008) and it may strongly interact with the potential yield level of the environment. Both features may contribute to increased random yield variation and thus reduce the significance of correlations between yield and weed competitiveness or between yield and the VCU value for straw length. Finally, as the environments where weed pressure was measured received mechanical weed control by harrowing (Hansen et al. 2008), the environment-specific weed characteristics (Table 3) expressed the actual weed pressure as affected by harrowing and it was assumed that harrowing did not interact with the varieties (Hansen et al. 2007). The model predicted higher yields for tall varieties than for short varieties in the absence of competing non-crop plants (however, nonsignificant) as well as in environments with heavy infestation of creeping weeds.

Among the four diseases, leaf rust data displayed the best fit with the models (Fig. 1) whereas powdery mildew showed the largest deviations especially for susceptibility group 1; these deviations were most likely due to correlations between mildew susceptibility and one or more varietal characteristics that were not considered in the model. Model results further implied, however only with a significant effect for net blotch, that susceptible varieties tend to have higher yields than resistant varieties in diseasefree environments (Fig. 5). There are contradictions in the literature as to whether varietal disease resistance is costly with respect to yield (Purrington 2000). However, it seems to be widely recognised that the mlo-resistance against powdery mildew in spring barley indeed is costly for the plant (Brown 2002). According to the models, susceptible varieties, on the other hand, suffer higher disease-induced yield losses than resistant varieties in environments with high disease loads. These findings, although not surprising, indicate that our modelling approach is biologically coherent and realistic.

The predicted yield impact of individual diseases was highest for leaf rust, for which the most severe losses were predicted for a given disease severity level in a given environment (Fig. 5), while for scald the predicted yield impact was low and not significant (Fig. 1). The high impact of leaf rust on spring barley, in comparison to similar severity levels of other foliar diseases, is in accordance with recent yield loss observations in Danish conventional variety trials with fungicide-protected and unprotected plots (Pedersen 2007). Also, the predicted yield loss of up to $10-15 \%$ for both powdery mildew and net blotch, respectively, and even more for leaf rust (extrapolated from Fig. 5), is within the range observed in the Danish conventional variety trials in 2007, a favourable year for powdery mildew, net blotch and leaf rust epidemics in barley. These trials did not allow a separation of the effects of the individual diseases which according to our analyses may be a problem: our analysis indicated that the yield losses caused by simultaneous occurrence of powdery mildew and leaf rust were less than additive, i.e., less than the sum of losses caused by each individual disease.

Data of Whelan et al. (1997), who observed yield losses due to leaf rust of up to $63 \%$, underline the tremendous damage potential of leaf rust. In comparison, net blotch has been observed to cause up to about $34 \%$ yield loss in barley, depending on the variety (Khan 1987a, b). From the work of Hänsel (2001), who estimated the yield potential of barley genotypes by correcting the phenotypic yield for the yield decreasing effect of disease infection, 
substantial yield gaps due to genotype-specific powdery mildew susceptibility were estimated for spring barley varieties and also other studies have shown a substantial yield loss potential of powdery mildew, e.g. Newton and Thomas (1994) observed yield gains of up to $31 \%$ following fungicide application in mildew-infected barley.

Implications for variety testing, organic plant breeding and barley production

The results clearly showed that actual spring barley yields, obtained under conditions where no chemical pest control was available, highly depended on the resistance and tolerance properties of individual varieties. Varietal resistance thus highly contributes to closing environment-specific yield gaps (sensu Pinnschmidt et al. 1997) and reduces yield losses imposed by biotic stresses. Although the genetic potential for the complex trait weed competitiveness may be low, planting tall varieties may be a beneficial and supplemental tool along with mechanical weeding and intelligent crop rotation. In the future, VCU information needs to be applied together with other tools for crop protection, e.g., as in the Danish Crop Protection Online, which is based on disease and weed assessments in individual fields and considers crop phenology and previous fungicide treatments, coupled with disease resistance groupings, disease control thresholds and the risk that a particular disease is present, as estimated based on historical data (e.g. Hovmøller and Henriksen 2008).

Plant breeders will have to consider that stress resistance and tolerance properties of cultivars are particularly important in low-input systems where a lack of resistance to prevailing diseases or other stress factors directly translates into yield losses. Thus, breeding for varietal resistance against biotic and abiotic stresses becomes even more important. For variety testing, it is necessary to challenge genotypes with representative levels of multiple stresses either in testing environments covering a representative range of naturally occurring stresses, e.g. in multienvironment trials like in the present study, or in carefully manipulated trials under low-input conditions, such as inoculated disease nurseries and infested weed trials. VCU variety testing will thus yield information that helps to quantify the expected yield impact of biotic stresses and to choose adequate genotypes for crop production in particular environments as well as to select promising breeding material.

VCU information from high-input conventional trials was used in this analysis. There is still a debate ongoing about whether the information derived from such trials is applicable to organic cropping conditions or whether organic farming requires separate "organic" variety testing. This would be the case, for instance, if varieties rank significantly different in organic variety testing, as compared to the conventional VCU trials. This question was recently addressed using some of the data of the present study (Østergård et al. 2005; Przystaski et al. 2008). Østergård et al. used factorial regression to explain variation in observed grain yield in organic as well as conventional low-input trials by means of conventional VCU information of the previous year (significant effects of disease severity, date of ripening and 'competition' index). Only slightly better prediction of the grain yield obtained in conventional systems was found, as compared to organic systems. This indicates that the value of having two separate testing systems with respect to the tested characters may be questionable. Similar conclusions were drawn by Przystalski et al. (2008). Any future organic VCUtesting should, therefore, take additional varietal characteristics of specific importance for organic farming into consideration, such as direct measures of weed competitiveness, nutrient uptake efficiency and different quality aspects. The decision for implementation of independent organic VCU-testing will, however, ultimately depend on an evaluation of the economic costs and benefits.

Acknowledgement The data for this analysis have been collected by people at Danish Plant Directorate, Division of Variety Testing, Tystofte, under the guidance of Jakob W. Jensen. We wish to express special thank to Susanne A. Sindberg for data collection. The work has partly been funded by the DARCOF II-VI project BAR-OF. Discussions within the COST860 SUSVAR Network are acknowledged.

\section{References}

Akaike H (1974) A new look at the statistical model identification. IEEE Trans Automat Contr AC-19:716-723

Baril CP, Denis J-B, Wustman R, Van Eeuwijk FA (1995) Analysing genotype by environment interaction in Dutch potato variety trials using factorial regression. Euphytica 82:149-155 
Bond W, Grundy AC (2001) Non-chemical weed management in organic farming systems. Weed Res 41:383-405

Box GEP, Hunter WG, Hunter JS (1978) Statistics for experimenters. Wiley, $653 \mathrm{pp}$

Brancourt-Hulmel M, Denis J-B, Lecomte C (2000) Determining environmental covariates which explain genotype environmental interaction in winter wheat through probe genotypes and biadditive factorial regression. Theor Appl Genet 100:285-298

Brown JKM (2002) Yield penalties of disease resistance in crops. Curr Opin Plant Biol 5:339-344

Bundessortenamt (2007) Beschreibende Sortenliste. Getreide, Mais, Ölfrüchte, Leguminosen, Hackfrüchte. Deutscher Landwirtschaftsverlag GmbH, 278 pp

Christensen S (1995) Weed suppression ability of spring barley varieties. Weed Res 35:241-247

Dansk Landbrugsrådgivning (2007) Sortsfors $\emptyset$ g 2007 (Variety trials 2007). Dansk Landbrugsrådgivning, Landscentret, Planteproduktion, $53 \mathrm{pp}$

Dansk Landbrugsrådgivning (2008a) SortInfo. Retrieved 11 April 2008 from http://www.sortinfo.dk

Dansk Landbrugsrådgivning (2008b) Results from the official variety trials in Denmark. Retrieved 11 April 2008 from http://www.planteinfo.dk/Obsparceller/ index.html?item_id=408\&appl=0

Denis J-B (1980) Analyse de regression factorielle. Biom Prax 20:1-34

Digby PGN (1979) Modified joint regression analysis for incomplete variety $\times$ environment data. J Agric Sci Cambridge 93:81-86

Evans LT, Fischer RA (1999) Yield potential: its definition, measurement, and significance. Crop Sci 39:1544-1551

Goldberg D (1990) Components of resource competition in plant communities. In: Grace JB, Tilman D (eds) Perspectives in plant competition. Academic Press, San Diego, pp 27-49

Hansen PK, Rasmussen IA, Holst N, Andreasen C (2007) Tolerance of four spring barley (Hordeum vulgare L.) varieties to weed harrowing. Weed Res 47:241-251

Hansen PK, Kristensen K, Willas J (2008) A weed suppressive index for spring barley (Hordeum vulgare L.) varieties. Weed Res 48:225-236

Hovmøller MS, Henriksen KE (2008) Application of pathogen surveys, disease nurseries and variety resistance characteristics in an IPM approach for the control of wheat yellow rust. Eur J Plant Pathol 121:377-385

Hänsel H (2001) Yield potential of barley corrected for disease infection by regression residuals. Plant Breed 120:223226

Jørgensen LN, Kudsk P (2006) Twenty years' experience with reduced agrochemical inputs: Effect on farm economics, water quality, biodiversity and environment. HGCA R \& D Conference on Arable Crop Protection in the Balance Profit and the Environment, Lincolnshire (GB). http://www.hgca. com/publications/documents/cropresearch/Paper_16_Lise_ Jorgensen.pdf. Cited 9/4 2008

Kang MS, Gauch HG (1996) Genotype-by-environment interaction. CRC Press, 416 pp

Khan TN (1987a) Relationship between net blotch (Drechslera teres) and losses in grain yield of barley in Western Australia. Aust J Agric Res 38:671-679
Khan TN (1987b) Effect of spot-type net blotch (Drechslera teres (Sacc.) Shoem) infection on barley yield in short season environment of Northern Cereal Belt of Western Australia. Aust J Agric Res 40:745-752

Kristensen K, Ericson L (2008) Importance of growth characteristics for yield of barley in different growing systems: will growth characteristics describe yield differently in different growing systems? Euphytica (this issue)

Kristensen K, Hill J (2002) Multi-environment variety trials: analysis and prediction. In: Variety trials in sugar beetmethodology and design, vol 4. Advances in sugar beet research. International Institute for Beet Research, Bruxelles, Belgium, pp 19-54

Lemerle D, Verbeek B, Coombes NE (1995) Losses in grain yield of winter crops from Lolium rigidum competition depend on crop species, cultivar and season. Weed Res 35:503-509

Lin CS, Binns MR, Lefkovitch LP (1986) Stability analysis: where do we stand? Crop Sci 26:894-900

Madden L, Nutter FW (1995) Modeling crop losses at the field scale. Can J Plant Pathol 17:124-137

McCulloch CE, Searle SR (2001) Generalized, linear, and mixed models. Wiley, New York, 325 pp

Newton AC, Thomas WTB (1994) Detection of tolerance of barley cultivars to infection by powdery mildew (Erysiphe graminis f. sp. hordei). Euphytica 75:179-187

NIAB (2008) NIAB Spring combinable crops pocketbook. Varieties of cereals, oilseeds \& pulses. National Institute of Agricultural Botany (NIAB), Huntingdon Road, Cambridge, UK, CB3 OLE, 215 pp

Østergård H, Kristensen K, Jensen JW (2005) Prediction of grain yield of spring barley varieties by disease and growth characteristics from VCU testing. In: Köpke U, Niggli U, Neuhoff D, Carnish P, Lockeretz W (eds) Researching sustainable systems. Proceedings of the first scientific conference of the international society of organic agriculture research (ISOFAR), Adelaide, South Australia, 21-23 September 2005, pp 154-157

Patterson HD, Williams ER, Hunter EA (1978) Block designs for variety trials. J Agric Sci Cambridge 90:395-400

Paul H, van Eeuwijk FA, Heijbroek W (1993) Multiplicative models in cultivar by location interaction in testing sugar beets for resistance to beet necrotic yellow virus. Euphytica 71:63-74

Pedersen JB (2007) Oversigt over landsfors $\emptyset$ gene 2007 (Overview of national crop trials 2007). Dansk Landbrugsrådgivning, Landscentret, Planteproduktion, pp 114-125

Piepho HP (1998) Methods for comparing the yield stability of cropping systems-a review. J Agron Crop Sci 180:193213

Pinnschmidt HO, Chamarerk V, Cabulisan N, dela Peña F, Long ND, Savary S, Klein-Gebbinck HW, Teng PS (1997) Yield gap analysis of rainfed lowland systems to guide rice crop and pest management. In: Kropff MJ, Teng PS, Aggarwal PK, Bouma J, Bouman BAM, Jones JW, Van Laar HH (eds) Applications of systems approaches at the field level. Kluwer Academic Publishers, Dordrecht, pp 321-338

Przystalski M, Osman A, Thiemt E, Rolland B, Ericson L, Østergård H, Levy L, Wolfe M, Büchse A, Piepho HP, 
Krajewski P (2008) Comparing the performance of cereal varieties in organic and non-organic cropping systems in different European countries. Euphytica (this issue)

Purrington CB (2000) Costs of resistance. Curr Opin Plant Biol 3:305-308

SAS Institute (2000) SAS OnlineDoc Version 8. SAS Institute Inc., SAS Campus Drive, Cary, North Carolina 27513, USA

Satterthwaite FE (1946) An approximate distribution of estimates of variance components. Biometrics Bull 2:110-114

Schwarz G (1978) Estimating the dimension of a model. Ann Stat 6:461-464

Tilman D (1990) Constraints and tradeoffs: toward a predictive theory of competition and succession. Oikos 58:3-15

Van Eeuwijk FA, Elgersma A (1993) Incorporating environmental information in an analysis of genotype by environment interaction for seed yield in perennial ryegrass. Heredity 70:447-457
Van Eeuwijk FA, Keizer LCP, Bakker JJ (1995) Linear and bilinear models for the analysis of multi-environment trials: II an application to data from the Dutch Maize Variety Trials. Euphytica 84:9-22

Whelan HG, Gaunt RE, Scott WR (1997) The effect of leaf rust (Puccinia hordei) on yield response in barley (Hordeum vulgare L.) crops with different yield potentials. Plant Pathol 46:397-406

Wolfe MS, Baresel JP, Desclaux D, Goldringer I, Hoad S, Kovacs G, Löschenberger F, Miedaner T, Østergård H, Lammerts van Bueren ET (2008) Developments in breeding cereals for organic agriculture. Euphytica (this issue)

Zhang XY, Loyce C, Meynard JM, Monod H (2007) Modelling the effect of cultivar resistance on yield losses of winter wheat in natural multiple disease conditions. Eur J Agron 26:384-393 